\title{
Desain dan Analisis Inverter Tiga Fasa untuk Aplikasi Sistem PLTS Terhubung Grid PLN sebagai Referensi
}

\author{
M. Yasin*1, Faizal Arya Samman ${ }^{1}$, Rhiza S.Sadjad ${ }^{1}$ \\ ${ }^{1}$ Teknik Elektro, Fakultas Teknik, Universitas Hasanuddin Makassar \\ Jl. Perintis Kemerdekaan Km. 10, Tamalanrea Indah, Makassar, \\ *Email: ysn_sw77@yahoo.com
}

\begin{abstract}
Abstrak
Paper ini memperlihatkan hasil simulasi dan analisis inverter tiga-fasa yang akan digunakan pada sistem pembangkitan listrik tenaga surya, yang berfungsi mengubah sumber arus searah dari panel surya menjadi arus bolak-balik. Dalam simulasi, inverter dimodelkan dan didesain dengan menggunakan tegangan referensi dari jala-jala PLN sebagai acuan untuk membangkitkan sinyal kendali PWM (Pulse Width Modulation). Sinyal PWM ini dikirimkan ke pintu gate dari komponen saklar transistor daya, yang dalam hal ini digunakan IGBT (Insulated Gate Bipolar Transistor). Pengaturan irama penyaklaran akan mengubah sumber tegangan DC (Direct Current) menjadi tegangan AC (Alternating Current). Dengan menggunakan filter pasif LC, maka sinyal keluaran dari inverter dapat diubah menjadi gelombang sinusoidal berfrekuensi $50 \mathrm{~Hz}$ sebagaimana diharapkan. Output sinyal inverter terhadap PLN memiliki perbedaan fasa sehingga disimulasikan sebuah mekanisme yang dapat mendeteksi beda fasa dan mengatur delay pwm sehingga output inverter dan sefasa dengan PLN. Hasil analisis menunjukkan bahwa tegangan fasa dan beda fasa dari keluaran inverter dapat diatur sesuai dengan tegangan pada fasa grid PLN.
\end{abstract}

\begin{abstract}
This paper shows the results of simulations and analysis of three-phase inverters to be used in solar power generation systems, which function to convert the direct current source from the solar panel into alternating current. In the simulation, the inverter is modeled and designed using the reference voltage of the PLN mesh as a reference to generate the PWM (Pulse Width Modulation) control signal. This PWM signal is sent to the gate door of the switch component of the power transistor, which in this case is used IGBT (Insulated Gate Bipolar Transistor). The switching cadence setting changes the DC Current (Direct Current) source to AC voltage (Alternating Current). By using LC passive filter, the output signal from the inverter can be converted into $50 \mathrm{~Hz}$ frequency sinusoidal wave as expected. The output of the inverter signal to the PLN has a phase difference so that it is simulated a mechanism that can detect the phase difference and adjust the pwm delay so that the inverter and in phase output with PLN. The results of the analysis show that the phase and phase voltages of the inverter output can be adjusted according to the voltage on the PLN grid phase.
\end{abstract}

Kata- Kunci : Inverter 3 Fasa, Grid PLN, IGBT, PWM.

\section{Pendahuluan}

Saat ini sumber energi yang paling banyak digunakan di dunia adalah energi fosil yang berupa bahan bakar minyak. Energi fosil adalah energi yang tak terbarukan dan akan habis pada beberapa tahun yang akan datang [1]. Energi alternatif merupakan solusi untuk mengganti kebutuhan akan energi fosil. Misalnya panas bumi, biomassa, sinar matahari, nuklir, dan sebagainya.

Kebutuhan energi listrik yang terus meningkat berpotensi menghasilkan overloads jaringan distribusi yang menciptakan masalah seperti pemadaman, ketidakstabilan grid, penurunan kualitas daya, keamanan daya dan sebagainya. Untuk menyeimbangkan kebutuhan energi, maka diperlukan pembangkit daya baru dan terbarukan seperti Photovoltaic (PV), Angin, dan Biomassa [2].

Piranti-piranti yang menghasilkan energi baru dan terbarukan misalnya saja sel surya menghasilkan tegangan dalam bentuk DC. Sehingga dibutuhkan sebuah inverter tegangan arus DC ke AC agar dapat di gunakan oleh peralatan listrik rumah tangga [3]. 
Untuk menyalurkan daya keluaran inverter yang bersumber dari PLTS dengan jaringan listrik dibutuhkan proses sinkronisasi dengan cara mengontrol kerja inverter sedemikian rupa sehingga diperoleh tegangan, amplitodo sesaat, fase dan frekuensi yang sesuai dengan jaringan listrik. Pengaturan sistem sinkronisasi dan pembentuk gelombang keluaran dilakukan dengan tegangan jaringan sebagai acuan.

Bila tegangan jaringan turun, maka tegangan inverter juga harus mengikuti, begitu sebaliknya. Demikian pula bila frekuensi jaringan listrik naik atau turun, maka frekuensi keluaran inverter juga harus dapat mengikutinya.

\section{Deskripsi Permasalahan}

Dalam tahap interkoneksi, masalah yang dihadapi adalah harmonisa keluaran inverter dan sinkronisasi fasa frekuensi tegangan keluaran inverter dan grid. Bila karakteristik daya listrik yang dihasilkan inverter tidak sinkron, dimungkinkan pengoperasian paralel akan mengakibatkan ketidakstabilan dan bahkan kegagalan pada jaringan distribusi. Sedangkan harmonisa atau masalah ketidakmurnian isyarat tegangan pada keluaran inverter akan berpengaruh kondisi ketahanan peralatan/perangkat listrik lainnya.

Paper ini akan memberikan suatu mekanisme sinkronisasi koneksi tegangan keluaran inverter dengan tegangan pada jaringan listrik PLN, dengan Total Harmonik Distortion (THD) yang sangat rendah. Sehingga didapatkan desain inverter on grid 3 fasa yang mampu mengubah arus DC menjadi arus AC kemudian menyalurkannya ke jaringan listrik utilitas (PLN).

Sebelumnya dilakukan simulasi model DC-AC converter untuk menemukan nilai komponen yang akan di gunakan pada modul inverter.

\section{Hasil Perancangan}

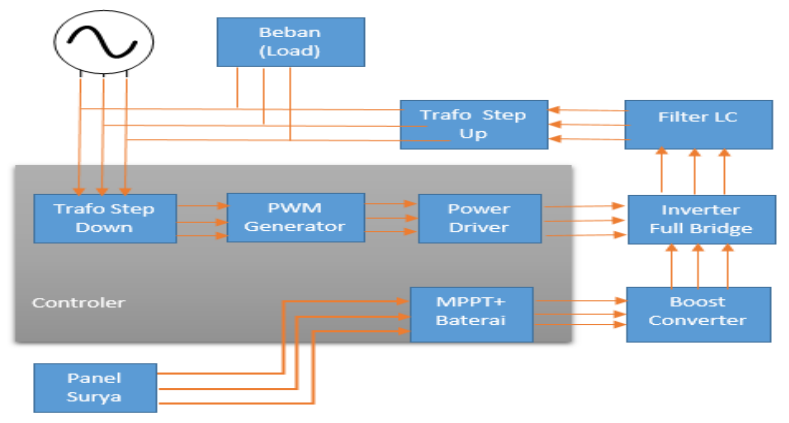

Gambar 1. Rancangan panel surya terhubung grid

3.1. Rangkaian Inverter tiga fasa dengan Pspice

Pada rangkaian inverter tiga fasa tanpa filter digunakan parameter-parameter seperti terlihat dalam Tabel berikut :

Tabel 1: Parameter Simulasi

\begin{tabular}{cc}
\hline Nama Parameter & Status \\
\hline V input & 220 volt DC \\
\hline V jala-jala (grid) & 380 volt AC \\
\hline Ra, Rb, Rc (beban Rload) & $50 \mathrm{ohm}$ \\
\hline La, Lb, Lc (beban Lload) & $5 \mathrm{mH}$ \\
\hline Switch & IGBT \\
\hline
\end{tabular}

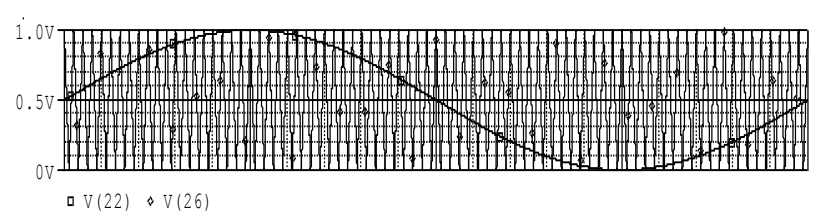

$\square \mathrm{V}(22) \diamond \mathrm{V}(26)$

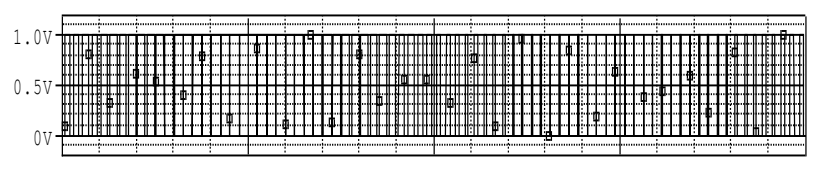

$\square \mathrm{V}(\mathrm{g} 1)$

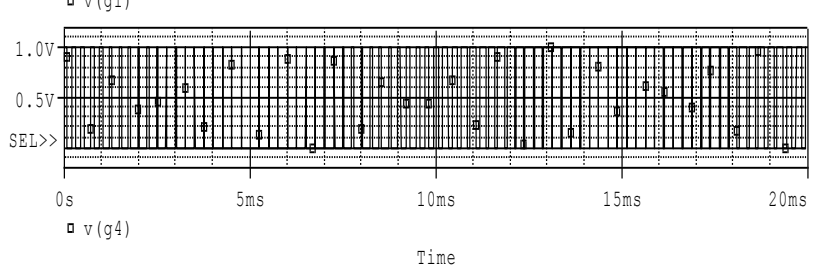

Gambar 2. Sinyal PWM yang dibangkitkan untuk gate 1 - 4

Gambar 2 merupakan hasil simulasi dari rangkaian inverter tanpa filter dimana gambar plot pada baris pertama menggambarkan input sinusoidal dari jala-jala PLN tiga fasa. Gambar plot pada baris kedua mengambarkan hasil keluaran dari inverter tanpa filter untuk fasa A. Gambar plot baris ketiga untuk fasa B dan untuk yang ke empat merupakan fasa $\mathrm{C}$ dari output 
inverter. Hasil simulasi memperlihatkan output keluaran mengikuti fasa input dari PLN tiap fase keluaran dari inverter.

Hasil simulasi dari rangkaian inverter dengan menggunakan filter dapat dilihat pada Gambar 4 Dalam simulasi digunakan filter LC dengan nilai komponen $\mathrm{L}$ sebesar $5 \mathrm{mH}$ dan nilai $\mathrm{C}$ adalah $1 \mathrm{uF}$ untuk masing-masing beban yang terhubung setiap fase ke ground. Hasil simulasi memperlihatkan pergeseran fasa sesuai dengan referensi input dari jala-jala PLN tetapi terdapat beberapa ketidak stabilan pada tegangan dengan penurunan tegangan input dari 50 volt tegangan input DC menjadi kurang lebih 30 volt tegangan output AC pada keluaran inveter yang telah di beri filter LC.

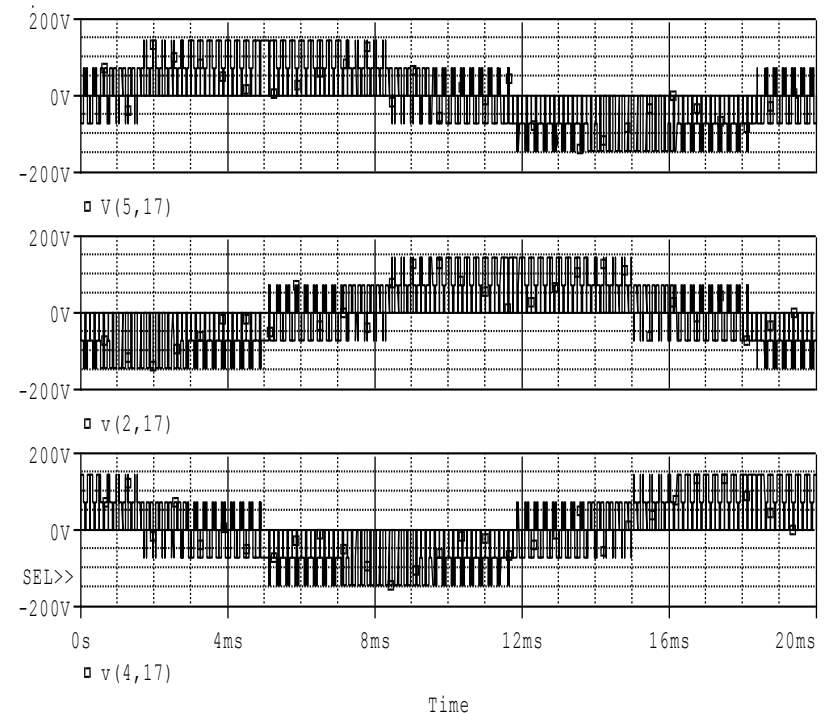

Gambar 3. Sinyal output inverter tanpa filter untuk fasa $\mathbf{R}, \mathbf{S}$ dan $T$

Filter yang digunakan adalah filter jenis LC. Komponen L ditambahakan pada tiap-tiap terminal fasa keluaran untuk mengoreksi nilai induktif pada beban RL yang sudah terpasang sebelumnya. Komponen kapasitor digunakan untuk memfilter riak yang dihasilkan dari tegangan keluaran.

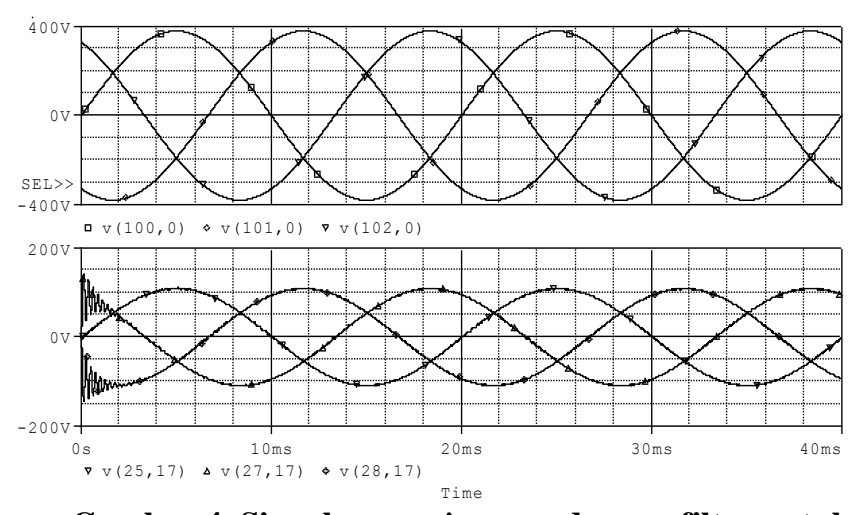

Gambar 4. Sinyal output inverter dengan filter untuk fasa $R, S$ dan $T$

Gambar 4 memperlihatkan hasil simulasi rangkaian dengan menggunakan filter LC. Gambar baris atas memperlihatkan tegangan untuk setiap 3 fasa dari jala-jala (grid). Pada bagian bawah, terlihat tegangan keluaran inverter untuk masing-masing ketiga fasanya. Pada saat awal, nampak terlihat kondisi peralihan tegangan keluaran yang berlangung kira-kira 2 millidetik.

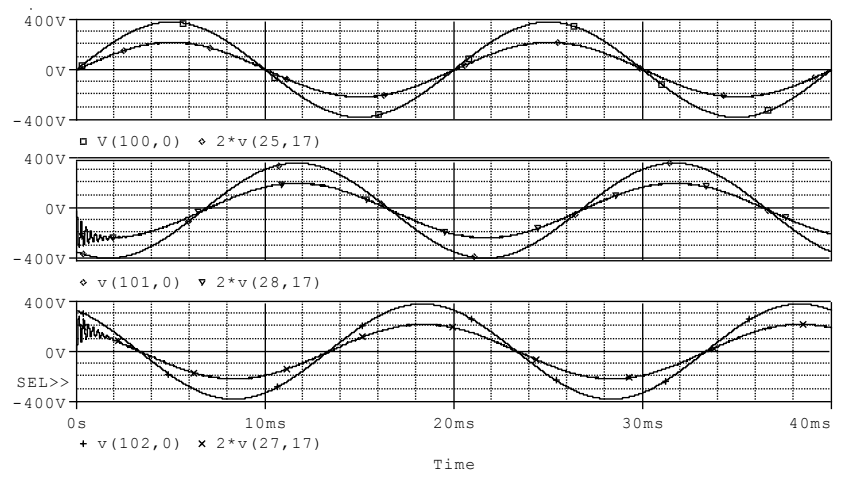

Gambar 5. Perbandingan sinyal PLN dengan output inverter

Gambar 5 memperlihatkan grafik perbandingan langsung antara tegangan jala-jala dengan keluaran inverter untuk setiap fasanya. Nampak terlihat bahwa tegangan keluaran inverter mengalami degradasi sehingga keluarannya hanya berkisar lebih besar sedikit dari 100V. Grafik keluaran inverter pada Gambar 9 diperbesar dua kali untuk melihat lebih jelas perbedaan fasa antara kedua tegangan tadi. Keluaran inverter dapat diperbesar dengan menggunakan misalnya trafo penaik tegangan. 
3.2. Mekanisme Sinkronisasi Inverter Terhadap Grid PLN

Proses perancangan mekanisme interkoneksi tidak menitikberatkan pada teori matematis tetapi lebih ke arah perancangan sistem digital agar dapat diterapkan langsung ke device FPGA.

Adapun rancangan mekanisme untuk sinkronisasi adalah sebagai berikut :

a. Proses Sampling : salah satu fasa dari tegangan Listrik PLN (misal fasa R) akan diturunkan oleh trafo step down dari 220 VAC menjadi 6 VAC. Begitu juga pada salah satu fasa dari tegangan inverter (misal fasa R) akan diturunkan juga oleh trafo Step down dari 220 VAC menjadi 6 VAC. Tegangan output trafo step down 6VAC akan dibandingkan terhadap titik nol oleh komparator jika tegangan sesaat lebih besar nol maka komparator berlogika $H i g h$ dan jika nilai tegangan sesaat lebih kecil atau sama dengan nol maka komparator berlogika Low.

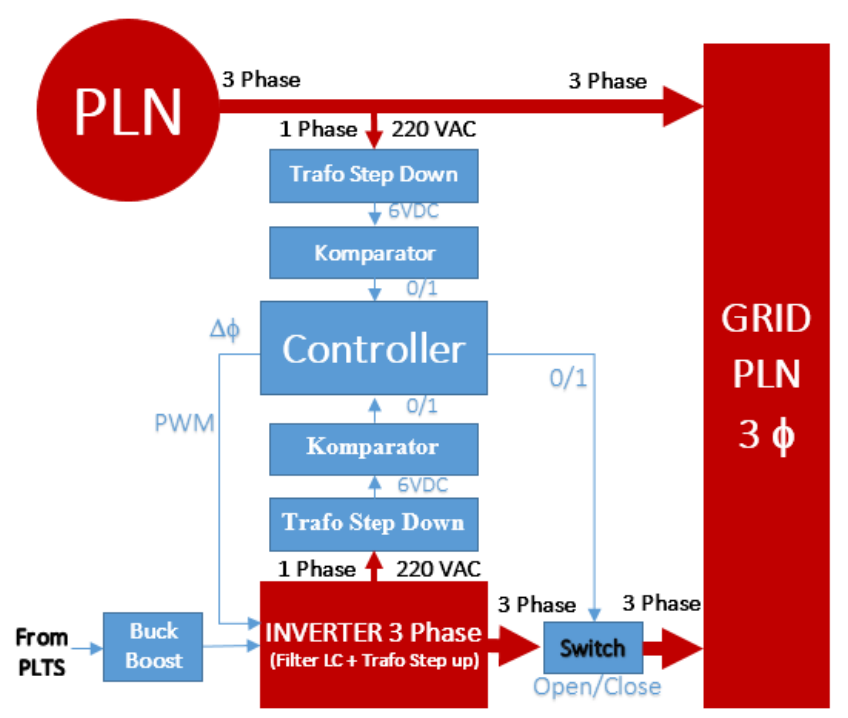

Gambar 6. Mekanisme sinkronisasi interkoneksi inverter dengan grid PLN

b. Proses Deteksi Beda Fasa : Logika tegangan dari komparator di sisi PLN dan komparator di sisi Inverter akan menjadi input oleh controller dan diolah sehingga mengeluarkan output berupa nilai beda fasa antara sinyal output Inverter dengan sinyal PLN. Nilai beda fasa dapat diperoleh dengan menghitung rentang waktu dimulai saat sinyal PLN terbaca dari nilai dibawah nol ke nilai di atas nol dan diakhiri saat sinyal output inverter terbaca dari nilai dibawah nol ke nilai di atas nol. Rentang waktu tersebut akan dibagi dengan periode 20 ms (Frekuensi $50 \mathrm{~Hz}$ ) dan hasilnya akan dikalikan dengan $360^{\circ}$. jika didapatkan sudut lebih besar dari $180^{\circ}$ maka nilai sudut tersebut akan dikonversi ke sudut di bawah $180^{\circ}$ dengan arah pergeseran lagging ke leading.

c. Proses Switching dan Sinkronisasi : Nilai beda fasa yang didapatkan oleh controller akan menentukan waktu delay pada PWM yang akan mengatur proses switching pada IGBT yang ada pada inverter tiga fasa. Sinyal hasil switching oleh IGBT akan difilter oleh filter LC sehingga didapatkan sinyal sinusoidal. Proses delay pada PWM berfungsi sebagai sinkronisasi fasa inverter terhadap PLN. Jika telah terjadi sinkronisasi dimana nilai beda fasa yang didapatkan masih berada dalam batas toleransi maka controller akan menutup switch sehingga sinyal output inverter tiga fasa dapat terkoneksi dengan Grid PLN. Jika belum sinkron maka controller akan membuka Switch

\section{Hasil Simulasi}

4.1. Pengujian Data Sampling Pembuatan Sinyal PWM

Sinyal PWM satu periode setara dengan frekuensi PLN $50 \mathrm{HZ}$ atau $\mathrm{T}=20 \mathrm{~ms}$ dibuat dengan membandingkan sinyal sinusoidal terhadap sinyal segitiga.

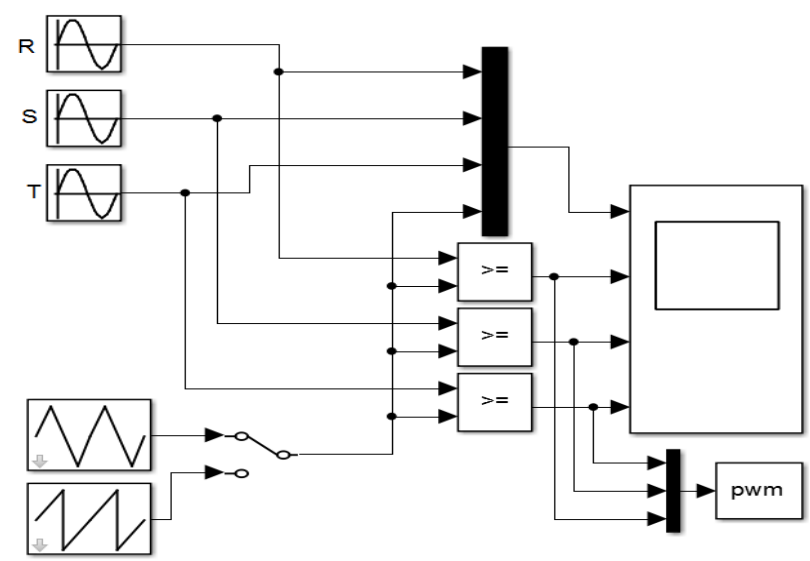

Gambar 7.Simulasi deteksi beda fasa sinyal inverter dengan grid PLN 


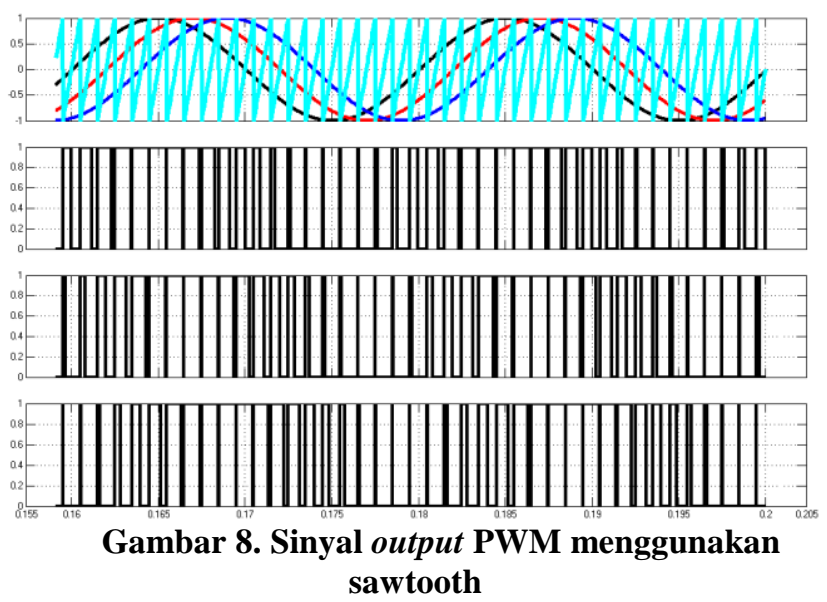

Dari Gambar 7 digunakan blok "to workspace" yang berfungsi untuk mengirim sinyal hasil simulasi PWM ke command window. Data PWM hasil simulasi sesuai Gambar 8 atau Gambar 9 dengan ukuran data sebesar 2331 x 3 yang artinya ada tiga sinyal PWM yakni untuk fasa $\mathrm{R}, \mathrm{S}$ dan $\mathrm{T}$ dengan masing-masing sinyal berjumlah 2331 data.

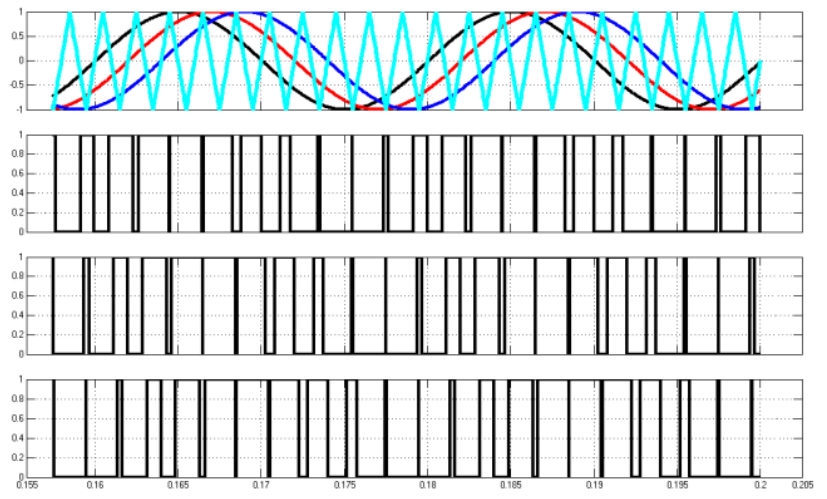

Gambar 9. Sinyal output PWM menggunakan triangle

4.2. Pengujian Data Kuantisasi PWM dengan Data Biner 8 bit

Tabel 2 : Hasil pengujian data PWM yang telah dikuantisasi menggunakan Counter Triangle

\begin{tabular}{cccccc}
\hline \multirow{2}{*}{$\begin{array}{c}\text { Counter } \\
\text { Triangle }\end{array}$} & \multicolumn{3}{c}{ PWM Signal } & & \\
\cline { 2 - 4 } & G1 & G3 & G5 & & Secoder \\
\hline 0 & 0 & 1 & 1 & 3 & 0.00 \\
\hline 1 & 0 & 1 & 1 & 3 & 1.41 \\
\hline 2 & 0 & 1 & 1 & 3 & 2.82 \\
\hline 3 & 0 & 1 & 1 & 3 & 4.24 \\
\hline 4 & 0 & 1 & 1 & 3 & 5.65 \\
\hline 5 & 0 & 1 & 1 & 3 & 7.06 \\
\hline 6 & 0 & 1 & 1 & 3 & 8.47 \\
\hline 7 & 0 & 1 & 0 & 2 & 9.88 \\
\hline 8 & 0 & 1 & 0 & 2 & 11.29 \\
\hline 9 & 0 & 1 & 0 & 2 & 12.71 \\
\hline
\end{tabular}

\begin{tabular}{cccccc}
\hline \multirow{2}{*}{$\begin{array}{c}\text { Counter } \\
\text { Triangle }\end{array}$} & \multicolumn{3}{c}{ PWM Signal } & & \\
\cline { 2 - 4 } & G1 & G3 & G5 & & Secoder \\
\hline 10 & 0 & 1 & 0 & 2 & 14.12 \\
\hline 11 & 0 & 1 & 0 & 2 & 15.53 \\
\hline 12 & 0 & 1 & 0 & 2 & 16.94 \\
\hline 13 & 0 & 1 & 0 & 2 & 18.35 \\
\hline 14 & 0 & 1 & 0 & 2 & 19.76 \\
\hline 15 & 0 & 1 & 0 & 2 & 21.18 \\
\hline 16 & 0 & 1 & 0 & 2 & 22.59 \\
\hline 17 & 0 & 1 & 0 & 2 & 24.00 \\
\hline 18 & 1 & 1 & 0 & 6 & 25.41 \\
\hline 19 & 1 & 1 & 0 & 6 & 26.82 \\
\hline 20 & 1 & 1 & 0 & 6 & 28.24 \\
\hline
\end{tabular}

Untuk menyederhanakan jumlah data PWM yang telah diuji pada tahap sebelumnya, maka data tersebut dikompres dengan metode interpolasi cubic menggunakan perintah Interpl seperti :

"pwmr=interp1 (tout', double (pwm $(:, 1))$ ' ,t', 'cubic') ;"

Dimana tout adalah jumlah data untuk waktu simulasi dan $\mathrm{t}$ adalah waktu pwm yang telah dikompress menjadi 256 data dengan menggunakan perintah

$" t=$ linspace $(0,0.02,256) ; "$

Tabel 3 : Hasil pengujian data PWM yang telah dikuantisasi menggunakan Counter Sawtooth

\begin{tabular}{cccccc}
\hline \multirow{2}{*}{$\begin{array}{c}\text { Counter } \\
\text { Sawtooth }\end{array}$} & \multicolumn{3}{c}{ PWM Signal } & & \\
\cline { 2 - 4 } & G1 & G3 & G5 & & \\
\hline 0 & 1 & 1 & 0 & 6 & 0.00 \\
\hline 1 & 1 & 1 & 0 & 6 & 1.41 \\
\hline 2 & 1 & 1 & 0 & 6 & 2.82 \\
\hline 3 & 1 & 1 & 0 & 6 & 4.24 \\
\hline 4 & 1 & 1 & 0 & 6 & 5.65 \\
\hline 5 & 1 & 1 & 0 & 6 & 7.06 \\
\hline 6 & 1 & 1 & 0 & 6 & 8.47 \\
\hline 7 & 1 & 1 & 1 & 7 & 9.88 \\
\hline 8 & 1 & 1 & 1 & 7 & 11.29 \\
\hline 9 & 1 & 1 & 1 & 7 & 12.71 \\
\hline 10 & 1 & 0 & 0 & 4 & 14.12 \\
\hline 11 & 1 & 0 & 0 & 4 & 15.53 \\
\hline 12 & 1 & 0 & 0 & 4 & 16.94 \\
\hline 13 & 1 & 0 & 0 & 4 & 18.35 \\
\hline 14 & 1 & 0 & 0 & 4 & 19.76 \\
\hline 15 & 1 & 0 & 0 & 4 & 21.18 \\
\hline 16 & 1 & 1 & 0 & 6 & 22.59 \\
\hline 17 & 0 & 1 & 0 & 2 & 24.00 \\
\hline 18 & 0 & 1 & 0 & 2 & 25.41 \\
\hline 19 & 0 & 1 & 0 & 2 & 26.82 \\
\hline 20 & 0 & 1 & 0 & 2 & 28.24 \\
\hline & & & & & \\
\hline
\end{tabular}


Dengan memilih jumlah data PWM sebanyak 256 data maka dibutuhkan delapan buah flip-flop $\left(256=2^{8}\right)$ agar dapat mencacah dari 0 hingga 255 hitungan. Pencacahan counter dari 0 hingga 255 hitungan akan setara dengan sebuah sinyal sinusoidal dengan fasa $\mathrm{R}$ dari $0^{0}$ hingga $360^{\circ}$. Fasa R, S dan T akan berbeda $120^{\circ}$ atau setara dengan 85 cacahan.

\subsection{Pengujian Pembuatan PWM Generator Berbasis FPGA}

Dengan mengacu pada Tabel 2 dan 3 yang ada pada tahap sebelumnya maka dapat dilihat bahwa sinyal PWM untuk fasa $\mathrm{R}, \mathrm{S}$ dan $\mathrm{T}$ bergeser 85 cacahan atau setara dengan $120^{\circ}$. Jika nilai biner dari sinyal PWM untuk fasa $\mathrm{R}, \mathrm{S}$ dan $\mathrm{T}$ dikonversi menjadi nilai cacahan, maka akan didapatkan urutan nilai cacahan tiga bit yang tidak berurutan yang terdiri atas nilai nol hingga tujuh.

Nilai cacahan tiga bit yang tidak berurutan sebanyak 256 kali dapat dibuat dengan membuat decoder 8 to 3 dengan kombinasi tabel kebenaran dapat dilihat kembali pada Tabel 2 proses pembuatan decoder dapat melalui proses penyederhanaan K-map (Karnough map) sehingga didapatkan persamaan aljabar boolean untuk nilai $\mathrm{R}$, $\mathrm{S}$ dan $\mathrm{T}$ kemudian dapat dirangkaian kombinasi gerbang-gerbang logika. Jika decoder ini diterapkan pada FPGA maka proses pembuatan decoder dapat diganti dengan instruksi penyeleksian seperti yang dapat dilihat pada lampiran "Listing Program Matlab : decoder8to3.m".

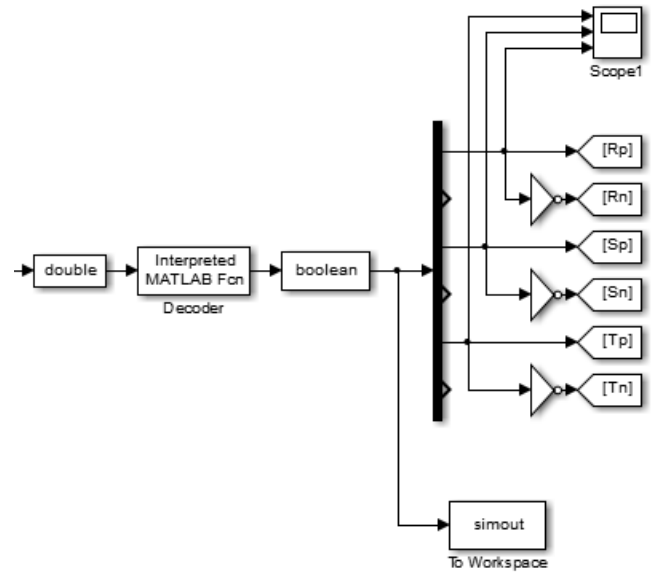

Gambar 10. Pembuatan diagram blok simulink untuk decoder PWM
4.4. Pengembangan Controller pada Mekanisme Sinkronisasi Inverter terhadap Grid PLN

Nilai clock pada Controller FPGA akan disesuaikan oleh sub sistem Clock Divider sehingga frekuensi clock yang masuk ke counter akan bernilai $12.8 \mathrm{MHz}$. Counter 8 bit, Decoder 8 to 3 dan Demux (demultiplexer) akan membentuk sebuah sub sistem "PWM generator" yang berfungsi untuk mengirimkan sinyal switching pada enam buah komponen IGBT.

Counter 8 bit dan Decoder 8 to 16 akan membentuk sebuah Sub sistem "Phase Detector" dimana sinyal Start sebagai pengatur reset counter akan didapatkan dari output Komparator dari sinyal Grid PLN. Sedangkan sinyal Stop sebagai pengatur pintu masuk sinyal clock pada counter akan didapatkan dari output komparator dari sinyal Inverter. Masing-masing sinyal dari grid PLN maupun dari inverter akan diturunkan terlebih dahulu oleh trafo step down sebelum masuk ke komparator.

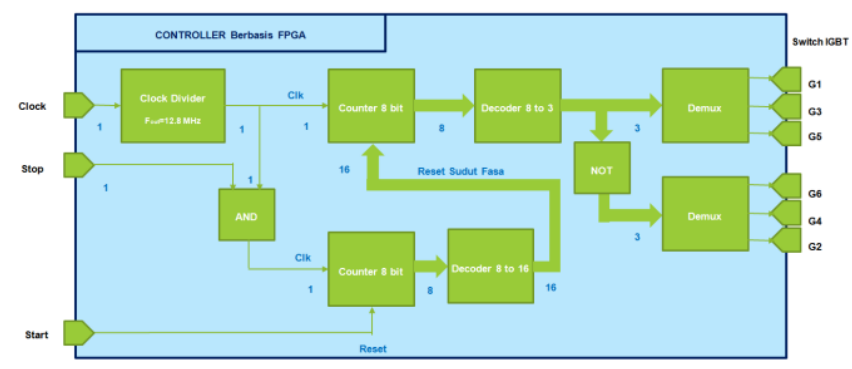

Gambar 11. Rancangan controller untuk sinkronisasi inverter terhadap grid PLN

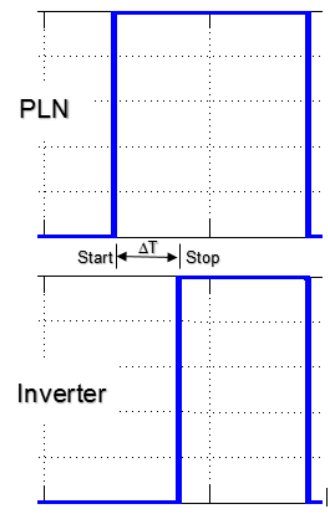

Gambar 12. Perhitungan waktu beda fasa antara PLN dengan inverter

Sub sistem PWM generator berupa clock, Counter 8 bit dan Decoder 8 to 3 telah berhasil disimulasikan pada laporan penelitian ini. Untuk sub sistem Phase Detector berupa Counter 8 bit 
dan Decoder 8 to 16 masih berupa rancangan yang dapat dikembangkan lebih lanjut. Nilai $\Delta \mathrm{T}$ yang didapatkan dari hitungan Counter 8 bit dapat diketahui nilai beda fasanya dengan melihat Tabel 2 dan 3 pada tahap pengujian sebelumnya. Nilai counter hasil perhitungan tersebut akan diubah oleh decoder 8 to 16 menjadi sinyal bit Set delapan bit dan sinyal bit Reset delapan bit. Kombinasi sinyal bit Set dan Reset untuk masingmasing flip-flop yang ada di PWM generator.

\section{Kesimpulan}

Mekanisme sinkronisasi koneksi tegangan keluaran inverter dengan tegangan pada jaringan listrik PLN telah dirancang dan sebagian telah diuji coba menggunakan matlab simulink dengan hasil pengujian bahwa sinyal R-S, sinyal S-T dan sinyal T-R telah bergeser dengan nilai beda fasa masing-masing $120^{\circ}$ atau 85 hitungan pada kecepatan clock $12.8 \mathrm{MHz}$.

\section{Referensi}

[1] Tim Contained Energy Indonesia. 2013.” Buku Panduan Energi yang Terbarukan". Program Nasional Pemberdayaan Masyarakat.

[2] Teodorescu, R., Liserre, M., \& Rodrigues, P. 2011. "Grdi Converters for Photovoltaic and Power Systems". ISBN: 978-0470-050751-3.

[3] Samman, F. A., Sadjad, R. S., \& Yasin, M. 2015. "Simulasi dan Analisis Inverter 3-Fasa dengan Sumber Referensi Tegangan pada Jala-jala PLN". Makassar: ISBN : 987-979-18011-1-9. 